This item was submitted to Loughborough's Research Repository by the author.

Items in Figshare are protected by copyright, with all rights reserved, unless otherwise indicated.

\title{
Revolutionary textiles: A philosophical inquiry on electronic and reactive textiles
}

PLEASE CITE THE PUBLISHED VERSION

https://doi.org/10.1162/desi_a_00574

PUBLISHER

MIT Press

VERSION

VoR (Version of Record)

PUBLISHER STATEMENT

HEINZEL, T. and HINESTROZA, J., 2020. Revolutionary textiles: A philosophical inquiry on electronic and reactive textiles. Design Issues, 36 (1), pp.45-58. () Massachusetts Institute of Technology. The journal's homepage is at https://www.mitpressjournals.org/loi/desi.

\section{LICENCE}

CC BY-NC-ND 4.0

\section{REPOSITORY RECORD}

Heinzel, Tincuta, and Juan P. Hinestroza. 2020. "Revolutionary Textiles: A Philosophical Inquiry on Electronic and Reactive Textiles". figshare. https://hdl.handle.net/2134/12093927.v1. 


\section{Revolutionary Textiles: A Philosophical Inquiry on Electronic and Reactive Textiles Tincuta Heinzel, Juan Hinestroza}

1 See, e.g., Sarah E. Braddock and Marie O'Mahony, Technotextiles: Revolutionary Fabrics for Fashion and Design (London: Thames and Hudson, 1998); and Matilda McQuaid and Philip Beesley, Extreme Textiles: Designing for High Performance (New York: Smithsonian Cooper-Hewitt, National Design Museum, 2005).

2 See, e.g., U.S. Department of Defense, “DoD Announces Award of New Revolutionary Fibers and Textiles Manufacturing Innovation Hub Lead in Cambridge, Massachusetts," https://www.defense.gov/ News/News-Releases/News-ReleaseView/Article/710462/dod-announcesaward-of-new-revolutionary-fibers-andtextiles-manufacturing-inno/ laccessed July 4, 2017); and Joanna Berzowska, “Electronic Textiles: Wearable Computers, Reactive Fashion, and Soft Computation," Textile 3, no. 1 (2005): 2-19.

3 Electronic textiles and wearable technologies often are placed in the same category. However, we suggest that these two domains should be addressed separately and in distinctive ways. Google Glasses are one example that illustrates the difference between these two fields; the glasses are wearable technology, without being electronic textiles.

4 See, e.g., Tincuta Heinzel, Mili John Tharakan, Ebru Kurbak, and Rebecca Stewart, "Parallel Industries," in Stitching Worlds: Exploring Textiles and Electronics, ed. Ebru Kurbak (Berlin: Revolver Publishing, 2018): 66-69; and Clint Zeagler, Thad Starnes, Tavernner Hall, and Maria Wong, Meeting the Challenge: The Path Towards a Consumer Wearable Computer (Atlanta: Georgia Institute of Technology, 2015).

5 Tincuta Heinzel, "Reactive Architecture, Augmented Textiles, Domotics and Soft Architecture Fabrication: On Electronic

\section{Introduction}

Often qualified as "revolutionary," electronic and reactive textiles are promising to bring wide-reaching changes to our existencefrom the way we dress to the way we communicate; from the way we sense and are sensed to the way we build and use textiles as substrates for new applications. ${ }^{1}$ The increasing interest in these "new" textile materials stems from the fact that their fields of application appear to be very broad, including military and medical fields, telecommunications, fashion, and art. ${ }^{2}$ However, neither electronic textiles nor wearable technologies, with which electronic and reactive textiles are often associated, have been adopted to the extent needed to speak of a revolution. ${ }^{3}$ Still, despite multiple research efforts related to electronic and reactive textiles, very few have made their entrance into our everyday life. Significant technical and industrial challenges must be overcome before the promised future arrives ${ }^{4}$; in addition, resistance to the adoption of such textiles also is a factor. ${ }^{5}$ Electronic and reactive textiles' ubiquityor rather, their promise of ubiquity-allows us to posit that textiles (in transformation) offer an exemplary case study for the present state of design as a discipline, forcing us to revisit design's approaches and to address issues ranging from science and technology, to ethical and aesthetic ones.

In this article, we explore, from a philosophical perspective, the revolutionary character of electronic and reactive textiles to address the question, what about them is "revolutionary"? Several corollary questions also arise: What do electronic and reactive textiles revolutionize? What is it to revolutionize? Or more precisely, "when revolution comes to textiles, what exactly is expected from them?" These questions help us to unpack the sense of the word "revolution" in the discourse of different actors in the field of textiles. They also help us to test the difference between discourse and technical reality, and to understand the links between technical changes and their effects in society. While acknowledging the constructivist position of design, we also investigate design's role(s) in addressing the present societal-technical configurations. ${ }^{6}$ 
and Reactive Textiles in Domestic Contexts," Textile 16, no. 1 (2018): 34-61, doi: 10.1080/14759756.2017.1332907.

6 Several works claim that design is a constructivist discipline. See, e.g., Herbert Simon, The Science of the Artificial (Cambridge, MA: MIT Press, 1996); and Theodore Zamenopoulos and Katerina Alexiou, "Towards an Anticipatory View of Design," Design Studies 4, no. 1 (2007): 411-36. Even design's orientation toward the future can be interpreted as a form of constructivism. See, e.g., Ramia Mazé, "Design and the Future: Temporal Politics of Making a Difference" in Design Anthropological Futures, eds. Charlotte Rachel Smith, Kasper Tang Vangkilde, and Mette Gislev Kjaersgaard (London: Bloomsbury Academic, 2016), 37-54.

7 Hannah Arendt, On Revolution (New York: Penguin Classics, 2006).

8 Thomas Kuhn, The Structure of Scientific Revolutions (Chicago: University of Chicago Press, 1962).

9 See, e.g., Lei Qian and Juan Hinestroza, "Application of Nanotechnology for High Performance Textiles," in Journal of Textile and Apparel, Technology and Management 4, no. 4 (2004): 1-8; and Matilda McQuaid, Extreme Textiles (New York: Princeton Architectural Press, 2005).

10 André Leroi-Gourhan, L'Homme et la matière [The Man and the Matter] (Paris: Albin Michel, 1971).
Revolutions generally are understood as eruptive moments that change the established order of things-an understanding arising from the French Revolution's ethos of revolution as a path to novelty, freedom, and irreversible breaches in the run of History. ${ }^{7}$ But "revolutions" also is a term widely used in science, from Copernicus's way of describing the regular, recurring, and cycling movements of the stars, to Thomas Kuhn's understanding of revolutions as paradigmatic changes in science, as a framework in which the scientific questions are defined and formulated. ${ }^{8}$ In light of these two definitions, we explore how the term is used in relation to electronic and reactive textiles.

If we take a closer look at the terminology used (e.g., smart textiles, electronic textiles, techno-textiles, nano-textiles, ${ }^{9}$ and "extreme textiles"), we notice the adjectives preceding each use of "textiles." In most cases, the adjective describes new functionalities of textiles-their "augmented" qualities. From this perspective, we can speak of electronic and reactive textiles as "more than textiles"-as textiles that introduce a difference when compared to most traditional ones. Therefore, if we want to understand exactly what electronic and reactive textiles revolutionize, we have to see what kind of changes they encompass compared to traditional textiles. The starting point of our analysis is precisely this difference.

Any comparison requires a reference system. To highlight the difference between traditional and new textiles, we use André Leroi-Gourhan's classification system of the elementary "forms of doing." ${ }^{10}$ Leroi-Gourhan's techno-morphological description is an unhistorical and essentialist account aiming to distinguish some permanent tendencies of intervention on the materials. Following his classification, textiles could be placed under what he called "flexible solids"-fiber materials that can be weaved or crisscrossed in different forms.

In this paper, we build our argument on three important points. First, we show that in the case of electronic and reactive textiles, we are confronted with a new understanding of matter (implying new ways in which that matter is manipulated and used). Second, we suggest that digitization not only affects the constitution of new objects (interactive objects/devices), but also produces changes in the industrial forms of production. Third, we argue that the innovation aspects related to the development of new materials and their forms of production have to be addressed at different scales, using trans-disciplinary approaches within a deliberate framework of philosophical questioning to do so. In this way we can facilitate efforts to bring together the paradigm-shifting innovations generated by science and technology; build bridges across high levels of disciplinary specialization and the web of relations existing between science, technology, and society; 
11 See, e.g., Gillian Barker and Philip Kitcher, Philosophy of Science: A New Introduction (Oxford: Oxford University Press, 2013), as well as Michel Foucault, Discipline and Punish: The Birth of the Prison (New York: Vintage, 1977); Philip Kitcher, "The Division of Cognitive Labor," in The Journal of Philosophy 87 , no. 1 (January 1990): 5-22; Bruno Latour, Science in Action: How to Follow Scientists and Engineers Through Society (Cambridge, MA: Harvard University Press, 1987); and Isabelle Stengers, Power and Invention: Situating Science, trans. Paul Bains (Minneapolis, MN: University of Minnesota Press, 1997).

12 Ezio Manzini, Design when Everybody Designs: An Introduction to Design for Social Innovation (Cambridge, MA: MIT Press, 2015).

13 Diana Mărculescu, Radu Mărculescu, Nicholas H. Zamora, Phillip StanleyMarbell, Pradeep K. Khosla, Sungmee Park, Sundaresan Jayaraman, et al., "Electronic Textiles: A Platform for Pervasive Computing," Proc. IEEE 91 , 1995-2018 (2003), https://doi. org/10.1109/JPROC.2003.819612 (accessed July 4, 2017).

14 Matteo Stoppa and Alessandro Chiolerio, "Wearable Electronics and Smart Textiles: A Critical Review," Sensors 14, (2014): 11957-92, doi: 10.3390/s140711957. and consider the emancipatory character of science and technology. ${ }^{11}$ The goal in doing so is to imagine, design, responsibly produce, and adopt "revolutionary textiles" in the context of the larger social, political, and economic structures.

After mapping the commonly accepted definitions of electronic and reactive textiles, we compare the elementary forms of fabrication for traditional, electronic, and reactive textiles. Using an integrative approach that mixes discourse analyses, science and technology descriptions, anthropological and aesthetic accounts, and critical reflection, we aim to create the conditions for the necessary translations between the different scales of investigation, from the nano-world to design's emancipatory social stances. ${ }^{12}$

\section{Revolutionary Textiles: Definitions and Developments}

Electronic and reactive textiles are the fabrics either that integrate electronic components and interconnections in their structure or that are fabricated so as to enhance their properties and to allow them to become sensitive to the environment. In both cases, the fabrics have the potential to transform themselves in sensors and actuators. When the reactive textiles are based on analogous reactions, electronic textiles have an increased capacity for computation-specific applications. ${ }^{13}$

In their overview of smart textiles developments, Matteo Stoppa and Alessandro Chiolerio define "smart textiles" this way: ... a broad field of studies and products that extend the functionality and usefulness of common fabrics. Smart Textiles are defined as textile products such as fibers and filaments, yarns together with woven, knitted or non-woven structures, which can interact with the environment/user. The convergence of textiles and electronics (e-textiles) can be relevant for the development of smart materials that are capable of accomplishing a wide spectrum of functions, found in rigid and non-flexible electronic products nowadays. Smart Textiles will serve as a means of increasing social welfare and they might lead to important savings on welfare budget. ${ }^{14}$

This definition shows that smart textiles not only are an innovative scientific research field, coupling textiles and electronics to enhance the functionality of textiles or to transform non-flexible electronics into flexible substrates, but also can serve as a means to increase social welfare. The main issues we encounter here, as in many technical papers, is that no detailed explanation of how a flexible electronic substrate can increase the social welfare is given.

This definition of smart textiles is very similar to an oftencited definition of "wearable computers" formulated by Joanna Berzowska in 2005: 
The "classic" (if that word can be used) definition of "wearable computers" refers to the act of wearing a computer on one's body.... The computer is decomposed into individual components (such as the motherboard, batteries, and wireless card), which are repackaged and distributed around the body in pockets.... Combined with personal wireless local area networks, communication tools, context-sensing software, and other people, the wearable computer can act as an augmented reality "intelligent" personal assistant.... The wearable computing vision implies that people in the future will wear personal computers in the same sense that we wear clothing, to facilitate context-dependent interactions with the world and the people in it. ${ }^{15}$

15 Joanna Berzowska, "Intimate Electronics, Wearable Computers, Electronic Textiles and Reactive Fashion," horizon zero 16 (July/August 2004), http://www. horizonzero.ca/textsite/wear.php? is $=16 \&$ file $=2 \&$ tlang $=0$ (accessed July 4, 2017).

16 Don Ihde, Bodies in Technology (Minneapolis, MN: University of Minnesota Press, 2001), xv.

17 Berzowska, "Intimate Electronics...."

18 For the former, see Anura Rathnayake and Tilak Dias, "Yarns with Embedded Electronics," in UbiComp/ISWC'15 Adjunct Proceedings (Osaka, Japan, September 2015), (New York, NY: ACM publications, 2015), 385-88, doi: $10.1145 / 2800835.2800919$. For the latter, see ed. Yael Kovo, "Technology Opportunity: Optical Fiber for Solar Cells," NASA booklet, 2015, https:// www.nasa.gov/ames-partnerships/ technology/technology-opportunityoptical-fiber-for-solar-cells (accessed July 4, 2017).

19 See Marshall McLuhan, Understanding Media: The Extensions of Man (New York: McGraw-Hill, 1964), Chapter 12 is titled "Clothing: Our Extended Skin." See also Joanna Berzowska, "Electronic Textiles: Wearable Computers, Reactive Fashion, and Soft Computation," Textile 3, no. 1 (2005): 2-19.
Defined in this way, wearable technologies not only are combining two worlds - those of textiles and electronics-but also are becoming ready-to-wear computers in direct contact with the body. Textiles here serve as a base-as a soft and a flexible physical support for memory and for digital manipulation systems conceived as interfaces between the wearer and the environment, resembling a "technological embodiment."16

However, the idea of "soft computation" is a bit of wishful thinking. Joanna Berzowska clarifies this point:

It is ironic that these wearable computers are in fact not very wearable-at least not in the same sense that a cashmere sweater is wearable. The various components are made of hard plastic, metal, and silicon. They are heavy and angular. In order for the wearable computer to be more wearable, we need to be able to knit it onto the body and replace wires with conductive yarns. We need electronic textiles. ${ }^{17}$

Things have evolved since Berzowska's text was published, although soft, flexible, and robust electronics that fit her description are still to be invented. This call for electronic textiles has been translated, in recent years, into a series of research efforts that seek to incorporate electronic components directly into fibers or to translate electronic components into fiber forms. ${ }^{18}$ And if cloth were already a medium, as Marshal McLuhan asserts, then "soft computation" built into clothing and wearables is now a new and hyper medium..$^{19}$ The role of artists and designers will then be, in good modernist tradition, to find the new medium's capabilities and limits, and to test its aesthetic performances. Even so, the fact is that if the modernist movement was reacting to the imposition of industry as the main form of production, then electronic and reactive textiles are to be seen as predecessors of an awaited revolution-one that hasn't yet found its expressions and its forms of production. 
Figure 1

Collage of book covers related to electronic and reactive textiles. Courtesy of the authors.
20 Matilda McQuaid, Extreme Textiles (New York: Princeton Architectural Press, 2005), 13.

21 The first attempts to produce synthetic fibers date from the nineteenth century, with Joseph Swan's cellulose-based fibers (1885) and Hilaire de Chardonnet's first artificial silk (1889). Nylon-the first fully synthetic fiber-was created in 1931 by Wallace Carothers at Du Pont. See David H. Keifer, An International Historic Chemical Landmark. The Establishment of Modern Polymer Science by Wallance H. Carothers (Wilmington, Delaware, USA: ACS Office of Communication, November 17 , 2000), https://www.acs.org/content/ dam/acsorg/education/whatischemistry/ landmarks/carotherspolymers/modernpolymer-science-wallace-h-carothershistorical-resource.pdf (accessed July 4, 2017).

22 See the catalogue of the exhibition "Künstliche Versuchung: Nylon-Perlon —Dederon, 1939-1999," organized by Haus der Geschichte der Bundesrepublik Deutschland. Haus der Geschichte der BRD [House of the History of the Federal Republic of Germany], Künstliche Versuchung: Nylon-Perlon-Dederon, 1939-1999 [Artificial Temptation: Nylon Perlon Dederon, 1939-1999] (Bonn, Germany: Wienand), 1999.

23 See Nicholas de Monchaux, Spacesuit: Fashioning Apollo (Cambridge, MA: MIT Press, 2011); and Ollessya Turkina and Damon Murray, Soviet Space Dog (London: FUEL Publishing, 2014).

24 See, e.g., P. Iribe and J. A. Lieske, Study of Extravehicular Protection and Operations, technical report (Washington, DC: National Aeronautics and Space Administration, 1967), https://ntrs.nasa.gov/ archive/nasa/casi.ntrs.nasa.gov/196700 20059.pdf (accessed July 4, 2017).

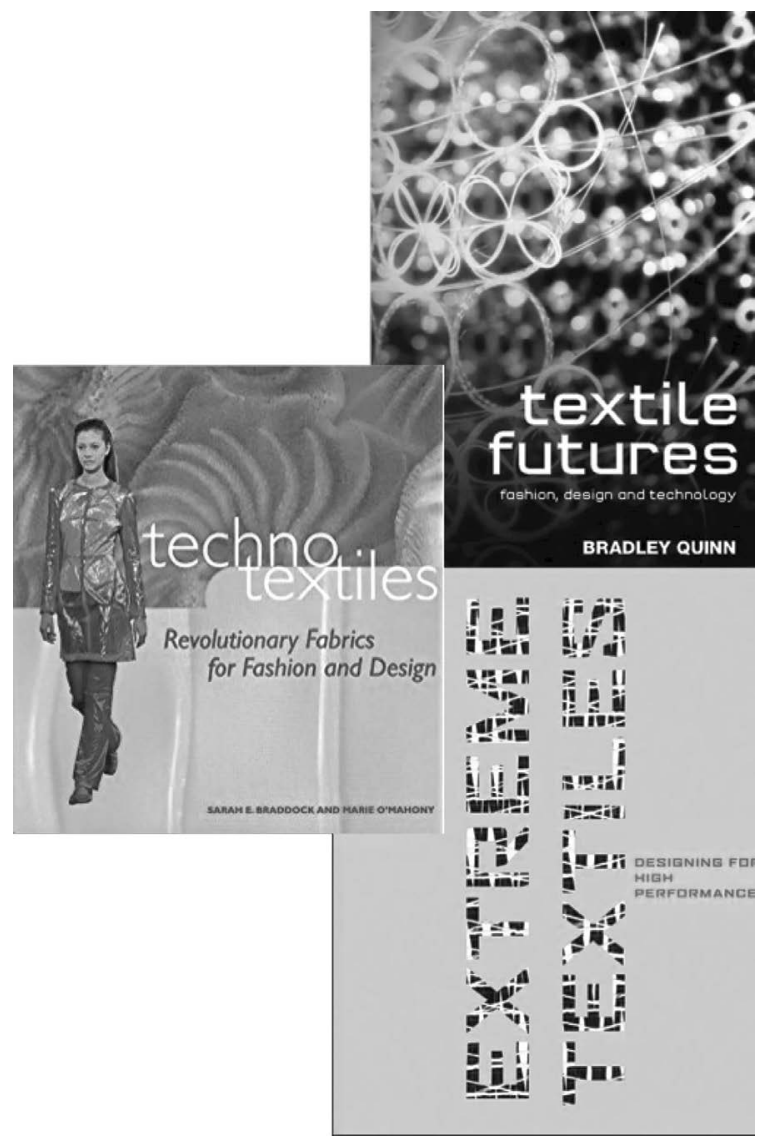

As for reactive textiles, they refer to fabrics made from materials that change form, color, and light intensity, in response to the environment (e.g., in response to temperature). Already in 2005, stronger, faster, lighter, safer, or smarter textiles were about to promise "a quiet revolution," as Matilda McQuaid formulated it ${ }^{20}$ one that changes our relationship to textiles without our even noticing (see Figure 1).

When did this revolution begin? And what caused it? The interest in electronic and reactive textiles can be traced back to the development of synthetic and technical fibers. ${ }^{21}$ Developments in materials science from the pre-World War II era and for war necessities (e.g., the invention of Nylon by Wallace Carothers and of Perlon by German chemist Paul Schlack) led to the development of highly functional fibers that in the 1950s could be further developed with a focus on domestic consumption. ${ }^{22}$ "Smart textiles" gained new ground with the emphasis on space research in the 1950s and $1960 \mathrm{~s}^{23}$; in this era, specialized equipment become a central part of military research..$^{24}$ Material sciences, nano-technologies, and computing communication technologies are some of the scientific fields now contributing to the development of wearable equipment. 


\section{Forms of Doing Electronic and Reactive Textiles}

With the development of electronic and reactive textiles, we must deal with a new way of understanding matter and a new way to manipulate and use it. This observation is based on what Bernadette Vincent-Bensaude has called a "materials by design" paradigm. ${ }^{25}$ This new scientific "genre" brings a new ontological status for different materials ${ }^{26}$ - one that no longer can be defined in terms of "materials' pre-requisite constraints on the process of design"; instead, the genre is defined by "materials specifically designed to gain certain properties." ${ }^{27}$

To explore how this new appropriation of matter in general, and of textiles in particular, can influence design processes, we turn to André Leroi-Gourhan's classification of "forms of doing" to compare the way in which traditional and new textiles are fabricated and manipulated. In his classification of flexible solids, Leroi-Gourhan distinguished between three essential forms of doing: 1) forming fibers and threads; 2) cutting and sewing; 3) contexture (e.g., knitting and weaving techniques).

\section{Forming Fibers and Threads}

The traditional way of producing fibers and yarns is to extract them from vegetal, animal, and mineral sources. Cotton (extracted from seeds), hemp (from stems), sisal (from leaves), and palm fibers, as well as wool, silk, or alpaca, are generally known as natural fibers. Most of them are processed through spinning. The socalled "human-made" fibers include cellulosics (e.g., acetate and lyocell), synthetics (e.g., nylon and polyester), and mineral fibers (e.g., metallic, carbon, and stainless steel fibers). Their production process follows different steps: preparing a melt or solution; forcing or extruding the solution through a spinneret; and later, solidifying it in the form of fibers via coagulation, solvent evaporation, or cooling. In the case of nano-fibers, the electro-spinning process implies that a solution or a melt is forced through a spinneret into an electric field that induces rapid elongation, hence producing fibers. ${ }^{28}$

To compare the manual spinning with electrospinning, we say that the latter is a mediated manipulation. In more concrete terms, the manual spinning process brings together into a thread a number of vegetal fibers or animal hairs, while in the case of electrospinning, the manipulation is at the molecular level and involves putting into the form of a fiber the molecules' degree of orientation and their crystallinity. All of these processes are necessary steps toward the functionalization of fibers to enhance the fibers' properties. In addition, in traditional textile fabrication, human hands put together the hairs and vegetal fibers in a long thread, while in electrospinning, the electric field controls the properties, the diameter, and the shape of the fibers. In most cases,

28 Sara Kadolph, Textiles, 11th ed. (London: Pearson, 2010), 161-222. 
Figure 2

Illustration of different scales of intervention related to textiles. Courtesy of the authors.
29 Ezio Manzini, The Material of Invention (Milan, Italy: Arcadia Edizioni, 1986); and Tincuta Pârv-Heinzel, Textiles électroniques et réactifs: fondements et textures [Electronic and Reactive Textiles: Foundations and Textures] (PhD thesis, Paris 1 University, February 2012).

30 Molecular machines are any discrete number of molecular components that produce quasi-mechanical movements (output) in response to specific stimuli (input). In 2016 the Nobel Prize in Chemistry was awarded to Jean-Pierre Sauvage, Sir J. Fraser Stoddart, and Bernard L. Feringa for the design and synthesis of molecular machines. The two types of molecular machines are molecular switches (or shuttles) and molecular motors (related to the trajectory). Computational chemistry was launched by Cyrus Lewenthal at MIT in 1970 and is based on the $\mathrm{X}$ rayons crystallography technique that aims to describe the reaction of a simulated molecule from a thermodynamic, electronic, and molecular conformity point of view. For a description of how this transformation happens. See also Sasha Loeve, Le concept de technologie à l'échelle des molecules-machines [The concept of Technology at the Scale of Molecular Machines] (PhD Thesis, Paris Ouest University, September 2009).

31 The two aspects explain the permanent need for new applications; only ubiquitous, application-driven transformation and development can make the research a success.

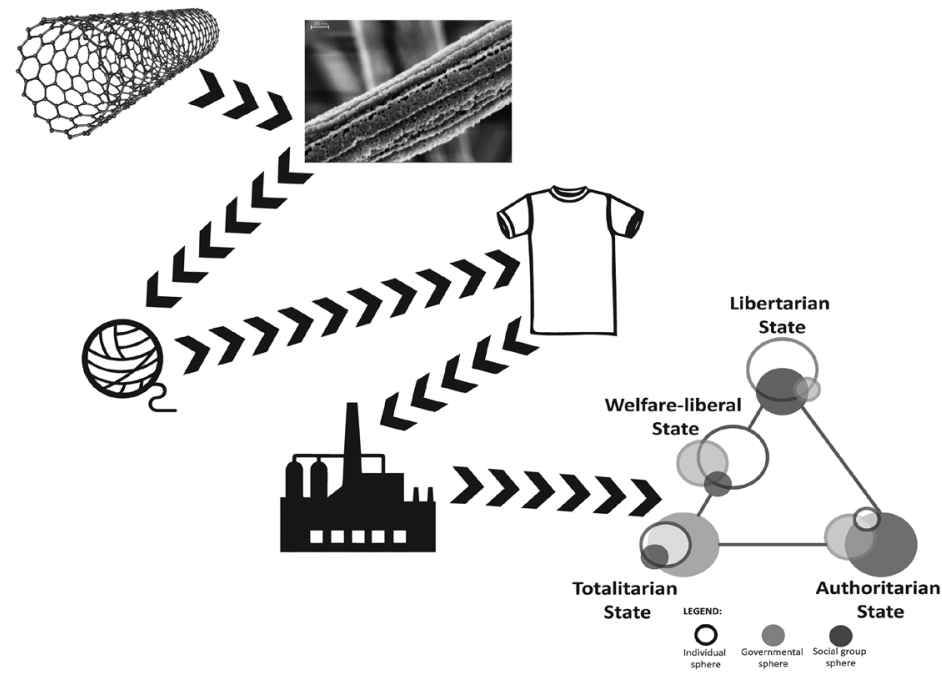

the functionalization of the resulting textile aims to enhance the properties - that is, to transform them into hydrophobic, sun, and flame-resistant or high tenacity fibers (e.g.; Kevlar, carbon fibers, etc.). If the aspect of the fibers does not suffer significant changes - for example, some of them might have the aspect of wool or silk-their functionalization is about changing the fibers' cultural identity. ${ }^{29}$

Moreover, because we are speaking about functionalization, we must keep in mind that every function is part of a system. Therefore, we can ask ourselves which system these new textiles are part of, and how we should define a nano-textiles system. Concepts like "molecular machines" or "computational chemistry" can help us understand the transformation of "materials into machines." ${ }^{30}$ Such conceptualization pushes us to rethink our assertions about technology - not only that we use tools to make the fibers, but also that we transform the materials into tools able to perform in different material configurations, for different purposes, and in different contexts of use. Most textile materials developed today find their raison d'être in relation to a certain use or application (e.g., hydrophobic or antimicrobial). Because of their ontological status, these materials require permanent innovation, which can be understood as problem-solving interventions both for the materials' configuration and for social issues. ${ }^{31}$

Still, the overlapping of technical problems with social issues creates confusion. The question that emerges is how a molecular structure, its properties, and its performances can deliver on the promises of a "bright future"? How can revolutionary research and innovation become a revolutionary enterprise and solve our societal problems? Can we create social change by controlling the alignment and the orientation of molecules or by collecting data from the body of the wearer? The answer is probably "yes," 
32 For the former position, see Victor Papanek, Design for the Real World: Human Ecology and Social Change (New York: Pantheon Books, 1971); and Ezio Manzini, Design, When Everybody Designs. An Introduction to Design for Social Innovation (Cambridge, MA: MIT Press, 2015). For the latter position, see Nigel Cross, “Designerly Ways of Knowing: Design Discipline Versus Design Science," in Design Issues 17, no. 3 (Summer 2001): 49-55.

33 Bernadette Bensaude-Vincent, Faut-II avoir peur de la chimie? [Should We Be Afraid of Chemistry?] (Paris: Les Empêcheurs de penser en rond, 2005).

34 Vanessa Nurock, "Nanoethics: Ethics for, from, or with Nanotechnologies?" in HYLE - International Journal for Philosophy of Chemistry 16, no. 1 (2010): 31-42.

35 Wampen's first anthropometric system for clothing, dated to 1864 , was translated and named by Hutcheson James Happle in 1903 as "Dr. Wampen's world renowned system of anthropometry as simplified and Americanized."

36 "See, e.g., Deepti Gupta and Norsaadah Zakaria, Anthropometry, Apparel Sizing and Design (Amsterdam: Woodhead Publishing, 2014).

37 Linsay Griffin, Crystal Compton, and Lucy E. Dunne, "An Analysis of the Variability of Anatomical Body References Within Ready-to-Wear Garment Sizes," in UbiComp/ISWC'16 Adjunct Proceedings, Heidelberg, Germany, September 2016 (New York, NY: ACM publications, 2016): 84-91, doi: 10.1145/2971763.2971800. but not in the most obvious way. Too many translations need to be taken into consideration to allow for interactions across different scales. Design primarily is seen as being in the position to negotiate between different stakeholders and to propose new methodologies and models ${ }^{32}$; the way to conceptualize interactions between different scales has yet to be addressed. And for this reason, philosophical inquiry must be integrated into scientific and design practices. As a systemic approach, philosophy has the capacity to investigate and to question very disparate and very specialized fields without falling into oversimplification (see Figure 2).

Another aspect of design's role needs philosophical inquiry. Bio- and nano-technologies now allow the mixing of biological structures with electronic and digital components. Mixing has always been chemistry's essence-halfway between natural sciences and technology ${ }^{33}$; however, we reached a stage where organic and inorganic have come together. Such a fusion raises ethical issues that are not easy to address. In which categories should these new configurations be included? What should the limits of technical interventions be, and what should the purpose of such enterprises be ${ }^{34}$ These questions are only a few of the matters that we need to address.

\section{Pattern Cutting and Sewing}

Following André Leroi-Gourhan's classification, the second essential form of doing related to flexible solids is pattern cutting and sewing. From an anthropologist's perspective, cutting is ahead of sewing or contexture because the oldest clothing pattern adjusted animals' skins for dressing purposes. Compared to the traditional ways of pattern cutting, we see two important advancements with the Industrial Age. The first one concerns human body measurements, and it is related to the standardization of these measurements. The German mathematician, Heinrich Wampen, developed a first standardized system for the measurement of clothing in industry in the nineteenth century. ${ }^{35}$ Today, the advancement of anthropometrics is the subject of large-scale studies. ${ }^{36}$ For electronic and reactive textiles, the issues are becoming even more complex and are related to the placement on the body of different sensors. The more precise we would like the placement of the sensors to be, the more we have to be oriented toward the personalization of electronic textiles. ${ }^{37}$

Another reason why personalization is a hot topic today is the need to overcome the returns of ready-to-wear items, and implicitly to reduce the losses of the industry. As a result, focus has turned to the personalization of serial production. This development goes hand in hand with the robotization of the industry, which allows for a more flexible calibration of the industrial 
38 Pârv-Heinzel, Textiles électroniques et réactifs [Electronic and Reactive Textiles: Foundations and Textures].

39 Geneviève Sevin-Doering is a French artist and costume designer who first developed a systematic body of research on a single piece of fabric cutting. See http://sevindoering.free.fr/ laccessed July 4, 2017). See also Rickard Lindquist, Kinetic Garment Construction (PhD thesis, University of Boras, Sweden, 2015), http://atacac.com/book/index.php\#index (accessed July 4, 2017).

40 See, e.g., Daina Tamina's crocheting objects to illustrate the hyperbolic space, http://www.math.cornell.edu/ dwh/ papers/crochet/crochet.html (accessed July 4, 2017); and Pârv-Heinze, Textiles électroniques et réactifs [Electronic and Reactive Textiles: Foundations and Textures], 94-100.

41 Abraham Moles, Elisabeth Rohmer, Art e tordinateur [Art and Computer] (Paris: Blusson Editeur, 1990), 244-48.

42 Elizabeth Landau, "'Space Fabric' Links Fashion and Engineering" in News of the Jet Propulsion Laboratory, California Institute of Technology. https://www.jpl. nasa.gov/news/news.php?feature=6816 (accessed July 4, 2017).

43 See e.g., Tincuta Heinzel, Mili John Tharakan, Ebru Kurbak, and Rebecca Stewart, "Parallel Industries" in Stitching Worlds: Exploring Textiles and Electronics ed. Ebru Kurbak (Berlin: Revolver Publishing, 2018): 66-69. See also the conclusions from the industrialization group's discussions at the E-textiles Summer Camp 2015, http://etextile-summercamp. org/2015/documentation-industrialization/ (accessed July 4, 2017); and Jay Walker, "Our System Is So Broken, Almost No Patented Discoveries Ever Get Used," in Wire (May 2015), https:// www.wired.com/2015/01/fixing-brokenpatent-system/ (accessed July 4, 2017). production. In this way, the balance between production and consumption is shrewdly controlled, making achievable the idea of "cybernetization" of the industry. ${ }^{38}$ This cybernetization refers to the processes of feedback between humans' needs and desires and the production lines that allow the control of the flux of production and consumption. The realization of such an industrial production line challenges the model of the free market, in which the balance is to be found in the free negotiation between offer and demand, and not in their technologically pre-established adjustment.

Another development to consider in relation to the cutting and sewing processes is about a change of approach in pattern making: from body-shapes toward body-movements. This new perspective, which facilitates the movements of the bodies (e.g., in sports contexts) was introduced by French dressmaker Geneviève Sevin-Doering in the 1970s and was later developed by Rickard Lindqvist. ${ }^{39}$

\section{Contexture}

The third essential form of doing related to flexible solids is that of contexture, according to Leroi-Gourhan. Contexture reunites all the techniques that can bring together different fibers, yarns, and threads. The techniques of contextures are actually mathematically-based models if we consider that felt, for example, is an unstructured fibers structure, that knitting and crochet are one-thread based structures, and that weaving is a double or multiple-threads structure..$^{40}$ Jacquard and tapestry techniques are multithread structures that allow independent, non-repetitive patterns to be weaved. In the same direction, we can also recall the Persian knots system, considered by many as the ancestor of pixel surfaces. The invention of the Persian knot made possible the realization of complex patterns by dividing the surface into small points and using color as a form of demarcation. ${ }^{41}$

Significant attention today focuses on the 3-D weaving and spacer fabric structures. ${ }^{42}$ Such fabrics can have different properties on each side-for example, with one side reflecting light and heat and the other absorbing it. Multilayer fabrics are an interesting area of research because they offer expanded possibilities for the further, and perhaps accelerated, development of electronic circuits and sensing fabrics.

Despite these developments, a real scale-up of an electronic textiles or reactive materials industry has not yet occurred. The reasons are multiple, but according to the actors in the field, they relate to the lack of adequate industrial technologies for the manufacturing of electronic and reactive textiles, the lack of interdisciplinary competencies, and the impediments related to the patent system (its fragmentation and its lack of open resources). ${ }^{43}$ This 
unique situation also changes the role of design in the industrial context: Whereas Bauhaus designers were trying to adapt the artisans' role to the context of industrial production, today's designers have to find new applications for innovations from different scientific research disciplines while developing new lines of production. The development of the Google Jacquard jacket illustrates this contemporary status of design. ${ }^{44}$ The jacket's design is less about the introduction of new technologies-most of the technology is open source, and similar projects already existed ${ }^{45}$-and more about finding the right functionalities for the jacket and putting together a production line.

\section{Textiles and Digitization}

Textile contextures are some of the oldest man-made technologies, and they have inspired some of the most modern digital technologies developments. Persian knots as the basis for pixels and the Jacquard punch card system are probably the most well-known examples. In the following sections, we examine how the digitization process affects both the development of interactive textile surfaces and their industrial production.

\section{Textiles Industry and Digitization}

The invention of the flying shuttle by John Kay in 1733 and the

44 Ivan Poupyrev, Nan Wei Gong, Shiho Fukuhara, Mustafa Emre Karagozler, Carsten Schwesig, and Karen E. Robinson, "Project Jacquard: Interactive Digital Textiles at Scale," in Proceedings of the 2016 CHI Conference on Human Factors in Computing Systems, 4216-27. https://dl.acm.org/citation. cfm?doid=2858036.2858176.

45 See Maurin Donneaud and Vincent Roudeaud's project, TextileXY(2005), licensed under Creative Commons Attribution Share-Alike 2.5, http:// xyinteraction.free.fr/wiki/pmwiki.php/ Main/HomePage (accessed July 4, 2017); and Maggie Orth, Emily Copper, Rehmi Post, Joshua Smith, and Joshua Strickon, "Musical Jacket" (1998), http://www. maggieorth.com/art_Jacket.html (accessed July 4, 2017).

46 Pierre-Damien Huyghe, Art et industrie (philosophie du Bauhaus) [Art and Industry. (Philosophy of Bauhaus] (Belval: Editions Circé, 1999), 19-20; and Jean-Claude Beaune, Philosophie des milieux techniques: La matière, I'instrument, l'automate [Philosophy of Technical Environments: The Matter, the Instrument, the Automate] (Seyssel: Champ Vallon, 1998), 203-21. invention of the Spinning Jenny machine by James Hargreaves in 1764 were the first steps toward a series of innovations in textiles' chain of manufacturing, marking what later would be called the Industrial Revolution. The increase in the amount of fibers and threads that resulted from the modernized spinning process created a need for their faster processing. The invention of Cartwright's Power Loom (1785) can be seen, then, as a logical development. The standardization and the systemic perspective imposed by the industrial model resulted from a new way of thinking that prioritized rationalization, with implications also for the organization of work and its social and economic impact. ${ }^{46}$

More recently, the textiles industry was one of the first to adopt digital tools. During the 1980s and 1990s, digitization in the textiles industry referred mostly to the introduction of software for pattern design processes. Following these developments, people in the industry used software tools to manage the chain of production and to facilitate distance work in a globalized textiles industry that divided the world into production sites (Eastern Europe, China and India) and development sites (Western Europe and the United States). Those in textiles industries now have turned their attention toward the simulation of textures and performances (folding) for textiles in an attempt to develop online fitting software and to reduce, in this way, the returns of online 
47 For discussions on roboticization, see, e.g., in the Saint Etienne Design Biennial 2017, which focused on the "Working Promesse: Shifting Work Paradigms," http://www.biennale-design.com/saintetienne/2017/en/home/ laccessed July 4, 2017); and Germany's national strategy for "Industry 4.0": https://ec.europa.eu/ growth/tools-databases/dem/monitor/ sites/default/files/DTM_Industrie\%20 4.0.pdf (accessed July 4, 2017). For experiments with basic revenue, see http://www.kela.fi/web/en/basicincome-experiment-2017-2018 (accessed March 4, 2017). In 2017-2018 Finland conducted the first government-backed European basic income experiment. For implications of the anthropocenewhich designates the era of significant human impact on the earth's geology and ecosystems - see Lucy E. Edwards, "What is the Anthropocene?" Eos 96, no. 30 (November 2015), doi: 10.1029/ 2015E0040297.

48 Facebook CEO Mark Zuckerberg spoke at Harvard University's 2017 Commencement about the need for a new social contract, in reference to Jean-Jacques Rousseau's "The Social Contract" (1762). See https://techcrunch.com/2017/05/25/ mark-zuckerberg-harvard/ (accessed July 4, 2017).

49 Tincuta Heinzel, "What's a Fabric? Concepts and Approaches to Modern Textile Design," Architectura 657, no. 3 (2015): 72-77.

50 Anna Vallgårda, Morten Winther, Nina Mørch, and Edit Emese Vizer, "Temporal Form in Interaction Design," International Journal of Design 9, no. 3 (2015): 1-15; and Lars Hallnäs and Jonas Redström, Interaction Design: Foundations, Experiments (Borås, Sweden: The Interactive Institute and the Swedish School of Textiles, University College of Borås, 2006), 228.

51 Tincuta Pârv-Heinzel, Textiles électroniques et réactifs [Electronic and Reactive Textiles: Foundations and Textures], 57-71. shopping systems. As noted, such developments are contributing to the cybernetization of the industry and are working hand in hand with the robotization of the textiles industry. These two forms of digital intervention in the production of textiles together are about to facilitate a personalized industrial production-an apparent oxymoron. In doing so, industry planners and developers are searching for a way to control all of the industry's phases, from production to consumption. Personalization thus proposes variants to already established models.

However, variations do not allow structural changes. From this perspective, we can critique these developments because they leave less space for invention-for the development of new products and alternative economic and technical forms. We must consider the implications of such models. Attempts to reposition the industrial society in the cybernetic age are reflected in discussions about the future of work in light of roboticized industrial models, in experiments related to the introduction of a basic revenue for everyone, and in concerns of the "anthropocene" movement about the rational use of resources (sustainability issues). ${ }^{47}$ As yet, none of these positions have advanced new, alternative systemic models that are able to rebalance the relationship between economy, technology, and society. Questions about what kind of economic model can support such developments and who has the authority to revise the "social contract" remain unresolved. ${ }^{48}$ The concerns are real, and the peril is to treat them for what they are not-as punctual technical problems-rather than addressing them in their global—political, social, and ethical—dimensions.

\section{E-Textiles and Physical Computing}

Electronic and reactive textiles bring together analogue and digital configurations, binding textiles and electronics. The mixture of textile materials and electronics, and the combination of digital technologies with different communication systems, have transformed textile fabrics from surfaces into interfaces. ${ }^{49}$ Such a transformation causes changes-not all of them expected. The most notable is the introduction of dynamic textile patterns, which introduces time as a new dimension of the design process. ${ }^{50}$ "Time" is not about a new dimension of the textiles per se (because materials can age $)^{51}$; instead, it refers to the design process for interactive textiles that aims to control and make recurrent some of textiles' new aesthetic properties-for example, the possibility of changing color in response to temperature changes or bio cues (through the use of thermochromic inks), the incorporation of light into the fabrics' structure (with the help of LEDs and fiber optics), and the presence of sound (through the use of electromagnetic field or the connection to sound devices). 
The construction of sensors into the structure of fabrics has important implications for the types of interactions humans have with them. New forms of interaction have been developed (e.g., stretching, folding, hanging), ${ }^{52}$ and new gesture vocabularies have been studied (e.g., loop movements). ${ }^{53}$ But the transformation of fabrics and clothing into sensors raises ethical questions. Sensing and tracking our bodies' reactions and our environment, putting them in connection with other devices, push us to question the nature of the collected data, as well as who controls it and what kind of protocols we are going to use in the flow of data exchange.

\section{Electronic and Reactive Textiles' Revolution}

In this paper we have sought to define the revolutionary character of electronic and reactive textiles. We have explored the shifts in the way we understand and manipulate matter to produce textiles, and in how digitization interferes both at the macro level (technoeconomic instances) and the micro level (interactive devices). The last question we consider is this: "What do we expect to be revolutionized in and about textiles?" The question is not easy to answer because it requires a diagnostic.

Many research studies related to electronic and reactive textiles refer to social welfare without explaining how a technical development can have an emancipatory role in society. The use of the term, "revolution," also produces confusion; as we noted, it has a double sense, referring both to the scientific revolutions that are adjusting the framework in which science is done and the kinds of questions to be answered, and to the eruptive social reaction against a status quo. The first sense is about defining and identifying the main issues to be researched; the second sense is about making violent changes in the course of events, to produce emancipatory results. The social-political revolutions cannot be detached from the "social question." ${ }^{4}$

One of the social questions that some of the actors of the "electronic textiles revolution" address is the democratization of science and technology. For Leah Buechley, creator of the LilyPad Arduino board, electronic textiles are halfway between textiles and electronics and can support alternative ways of doing engineering. ${ }^{55}$ The purpose in hybridizing old and new technologies is, according to Buechley, to help marginalized social groups appropriate the digital technologies and participate in their use-with a focus on women's access to technology. In other words, the revolutionary character of electronic textiles involves the relaunching, in very operative terms, of the debate on the access to technology and, with that, the debate on open science and technology. ${ }^{56}$ The revolution then can prompt social emancipation through education, where design serves as a platform for applied science and technology, impregnated with social concerns. erOpen, 2014): 17-47, doi: https://doi. org/10.1007/978-3-319-00026-8_2. 
If science education can offer tools for a better understanding of our technological environment, we also need to acknowledge that not all of our problems are of a scientific and technological nature. As Richard Feynman said in his reflections as a "citizen scientist," some of the problems are of a social and political nature, and they should be addressed as such. ${ }^{57}$ Becoming aware of the need for science to permanently doubt its premises-as well as of the plurality of the society and the need for independent institutions-Feynman encourages us to embrace this uncertainty in its capacity to offer a realist view of the world. He advises a more modest attitude, far away from the spectacular rhetoric of miraculous science and technology.

Contemporary advances in material sciences and digital economies are promising to challenge and disrupt our world's cultural, social, economic, and political structures. Most technologists and researchers take the narrow (and optimistic) perspective that shows how their interventions are going to "save the world." Still, the high degree of specialization in one field of science or industry can offer only a fragmentary perspective. The world's problems are complex, and the type of interventions needed relate to different scales (from nano to social). A silo environment, within which each discipline operates alone, leads to fragmentation and to institutional demarcations and competitiveness between scientific fields; it also affects the financing arrangements of science and technology, making interdisciplinary collaborations difficult to achieve.

Nevertheless, hope remains that science and technical interventions can actually change the world for the better. But then we should ask: To what extent do we need the change, and what exactly do we want to change? Who decides and who has the authority and the capacity to make a change? What kind of legislation do we have and what kind of legislation would be needed? These questions, and many others, are needed to reveal the complexity of the issues we are facing.

As the case of electronic and reactive textiles shows, a culture of transdisciplinarity must be embraced by the scientific community, in partnership with industry and community and governmental representatives, to create platforms of dialogue that facilitate interaction between different scales, as well as a much broader and more systemic view of the pros and cons of a broad acceptance of the anticipated revolution in electronic and reactive textiles.

Science and technology can catalyze change in the world, but scientists cannot neglect their responsibility for their actions. We not only must reflect on the social consequences of electronic and reactive textiles but also must think together with and within society about what it is to change. Some of the economic and political problems we face these days are the result of our failing 
institutions, more than of technological advancements. The "breaches" and schisms between the technological models and the economic and political models are wide, and yet they can be healed by a critical reflection. With this goal in mind, we plead for a greater presence of philosophy in science and design inquiry. Philosophy can help to establish design approaches in which the interaction between scales can be seen, where the complexity of the world can be addressed, where the scientific and socio-political paradigms can be questioned, and where the techno-scientific rhetoric can be deconstructed.

If design can help to reconfigure the world and to propose alternative economic and technological models, as well as to act as a mediator, translator, and agent between scales, then philosophy is needed to clarify the questions that should be addressed. A good question solves half of the problem.

\section{Acknowledgement}

We thank the Romanian - U.S.A. Fulbright Commission for supporting the research for this paper. 